

\title{
Structural and electronic properties of the metal cluster-based compounds including high concentration of solvent molecules
}

\author{
Norio Saito, P. Lemoine, Stéphane Cordier, Yoshitaka Matsushita, Takeo \\ Ohsawa, Fabien Grasset, Jeffrey Scott Cross, Naoki Ohashi
}

\section{To cite this version:}

Norio Saito, P. Lemoine, Stéphane Cordier, Yoshitaka Matsushita, Takeo Ohsawa, et al.. Structural and electronic properties of the metal cluster-based compounds including high concentration of solvent molecules. Journal of Inorganic and General Chemistry / Zeitschrift für anorganische und allgemeine Chemie, 2021, 647 (7), pp.751-758. 10.1002/zaac.202000427 . hal-03190344

\author{
HAL Id: hal-03190344 \\ https://hal.science/hal-03190344
}

Submitted on 19 Apr 2021

HAL is a multi-disciplinary open access archive for the deposit and dissemination of scientific research documents, whether they are published or not. The documents may come from teaching and research institutions in France or abroad, or from public or private research centers.
L'archive ouverte pluridisciplinaire HAL, est destinée au dépôt et à la diffusion de documents scientifiques de niveau recherche, publiés ou non, émanant des établissements d'enseignement et de recherche français ou étrangers, des laboratoires publics ou privés. 


\title{
Structural and electronic properties of the metal cluster-based compounds including high concentration of solvent molecules
}

\author{
Norio Saito, ${ }^{[a, b, c]}$ Pierric Lemoine, ${ }^{[\mathrm{d}]}$ Stéphane Cordier, ${ }^{[\mathrm{d}]}$ Yoshitaka Matsushita, ${ }^{[\mathrm{a}]}$ Takeo Ohsawa, ${ }^{[\mathrm{a}, \mathrm{e}]}$ \\ Fabien Grasset, ${ }^{[a, b]}$ Jeffrey Scott Cross, ${ }^{[c]}$ Naoki Ohashi* ${ }^{* a, c, e, f]}$
}

\begin{abstract}
Recrystallization of $\mathrm{Cs}_{2}\left[\mathrm{Mo}_{6} \mathrm{X}_{14}\right](\mathrm{X}=\mathrm{Cl}, \mathrm{Br})$ was examined using typical organic solvents, i.e., methanol $\left(\mathrm{CH}_{3} \mathrm{OH}\right)$, acetone $\left(\mathrm{CH}_{3} \mathrm{COCH}_{3}\right)$ and dichloromethane $\left(\mathrm{CH}_{2} \mathrm{Cl}_{2}\right)$ in order to modify crystal structures and optoelectronic properties by promoting purity or inducing insertion of guest molecules. To this context, we performed recrystallization in solvent liquid and exposure of $\mathrm{Cs}_{2}\left[\mathrm{Mo}_{6} \mathrm{X}_{14}\right]$ to vapor of those solvents. Subsequent single crystal $\mathrm{X}$-ray diffraction analyses revealed that three new types of compounds which contain high concentration of guest organic solvent molecules were obtained. Indeed, the newly found structures are $\mathrm{Cs}_{2}\left[\mathrm{Mo}_{6} \mathrm{Cl}_{14}\right] \cdot 3 \mathrm{CH}_{3} \mathrm{OH}$ and $\mathrm{Cs}_{2}\left[\mathrm{Mo}_{6} \mathrm{X}_{14}\right] \cdot 6 \mathrm{CH}_{3} \mathrm{COCH}_{3}$ belonging to triclinic $P \overline{1}$ space group, and $\mathrm{Cs}_{2}\left[\mathrm{Mo}_{6} \mathrm{X}_{14}\right] \cdot 4 \mathrm{CH}_{2} \mathrm{Cl}_{2}$ belonging to tetragonal $P 4 / m n c$ space group. Although breaking of centrosymmetry by insertion of the guest molecule is interesting in terms of optoelectronic properties, all those new compounds belong to centrosymmetric space groups. As DFT calculations for those new compounds show that the guest molecules, such as $\mathrm{CH}_{3} \mathrm{OH}$, do not affect the atomic arrangements and electronic features of the $\left[\mathrm{Mo}_{6} \mathrm{X}_{14}\right]^{2-}$ unit, they incorporated with the lattice while keeping with the electrostatic interaction between the $\left[\mathrm{Mo}_{6} \mathrm{X}_{14}\right]^{2-}$ and $\mathrm{Cs}^{+}$ions regardless of the very high concentration of the guest solvent molecules.
\end{abstract}

\section{Introduction}

Among the recent research directions in material science, exploiting the combination of the organic-inorganic networks as the crystalline solids has increasingly attracted great attention as the promising paradigm of designing the material structures and functionalities. For instance, the hybrid halide perovskites have been reported to exhibit the order-disorder phase transition evoked by the tumbling motion of the counter cations and intercalated organic molecules, leading to large ferroelectric response. ${ }^{1,2}$ Clathrate materials such as metal-organic frameworks (MOFs) $)^{3-6}$ and inclusion complexes ${ }^{7,8}$ are also known

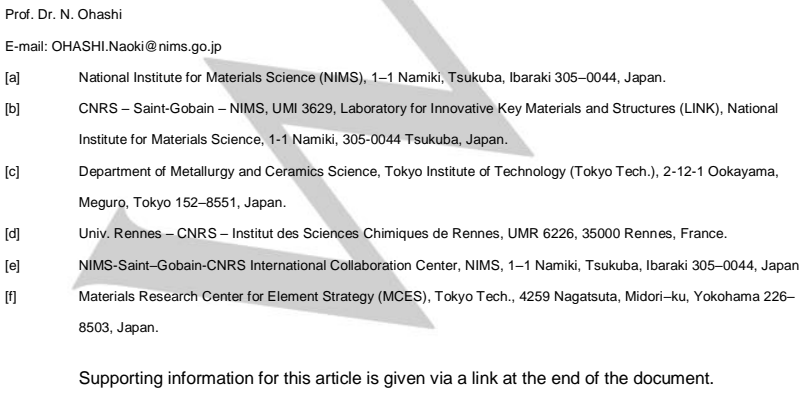

to be typical hybrid materials where possesses numerous large lattice spaces formed by the rational networking of the molecular building units, offering multifarious functionalities applicable to the molecular sieve, ${ }^{9,10}$ ion exchange ${ }^{11}$ and ionic conductor, ${ }^{12,13}$ etc. A common strategy among the material design of these hybrid compounds is to exploit the molecular features specific to the building blocks such as large molecular size, ${ }^{14}$ directional intermolecular interactions, ${ }^{3,6}$ thermal motion and orientational properties, ${ }^{15}$ leading to the attractive properties that have been never seen in inorganic components alone.

Octahedral metal clusters (MCs) are known to be the inorganic molecular building blocks introduced by Cotton in the 1960s. ${ }^{16}$ These MCs are surrounded by halogen ligands, and classified to two types of cluster units, i.e., the face-capped type expressed as $\mathrm{M}_{6} \mathrm{X}_{8} \mathrm{X}^{\mathrm{a}}{ }_{6}$ (M: transition metal; $\mathrm{X}^{\mathrm{i}}$ and $\mathrm{X}^{\mathrm{a}}$ : halogens at inner and apical sites) ${ }^{17-19}$ and the edge-bridged $M_{6} X_{12} X^{a_{6}}{ }^{20,21}$ It is well known that $\mathrm{V}$ and $\mathrm{VI}$ transition metals (e.g., Mo, W, Nb and Ta) can form those octahedral clusters. Particularly, $\left[\mathrm{Mo}_{6} \mathrm{X}_{8} \mathrm{X}_{6}\right]^{2-}$ cluster units have been widely studied because of their excellent photophysical features ${ }^{22,23}$ and solubility in diverse organic solvents. Because of the well-defined molecular structure and facile exchange reactions of the halogen ligands, structural design and property exploration of the MC compounds have been widely investigated. Saito et al and a few research groups reported that the crystallization of various charge transfer solids where the ionic association between $\left[\mathrm{Mo}_{6} \mathrm{X}_{14}\right]^{2-}$ and organic radical cations leads to exhibiting intriguing redox, transport and magnetic properties. ${ }^{24}$ In addition, some of these compounds crystallize in the anti-perovskite architecture that shows the antiferromagnetic behavior at low temperature. ${ }^{25,26}$ Several literature addressed to fabricate MOF like supramolecular nanostructures wherein the MCs are bridged via the apical linker ligands. ${ }^{27,28}$ As in above studies, the hybridization between the MCs and organic components allows us to extend the diversification of their crystal structure and thus extremely enlarge the material exploration fields.

In this context, we have been exploring the structures and functionalities of the MC compounds, particularly focusing on the crystallization of the MCs together with the organic solvent molecules. We hypothesize that this will lead to the formation of intriguing crystal structures, i.e., long-range lattice periodicity and non-centrosymmetric structure. We rely upon it that those compounds will potentially exhibit the structure-derived features such as ion trapping capability and piezoelectric nature. Indeed, it has been beginning that the solvent intercalation into the hybrid crystals is used as a way to control the packing dimension and to induce the non-centrosymmetric structure, giving interesting optical and electrical properties. ${ }^{2,29}$ In the present work, we 
inserted methanol $\left(\mathrm{CH}_{3} \mathrm{OH} ; \mathrm{MeOH}\right)$, acetone $\left(\mathrm{CH}_{3} \mathrm{COCH}_{3} ; \mathrm{ACTN}\right)$, and dichloromethane $\left(\mathrm{CH}_{2} \mathrm{Cl}_{2} ; \mathrm{DCM}\right)$ into the typical inorganic $\mathrm{MC}$ compounds, $\mathrm{Cs}_{2}\left[\mathrm{Mo}_{6} \mathrm{X}_{14}\right](\mathrm{X}=\mathrm{Cl}, \mathrm{Br})$, and successfully prepared the single crystal of new compounds which contains large amount of those solvent molecules. In addition, we studied the structural and physical properties of these MC-based solvent-inclusion compounds with various halogens $(X=\mathrm{Cl}, \mathrm{Br}, \mathrm{I})$ through theoretical calculations. Herein, we report their crystal and electronic structures and the effect of the solvent molecule on the stability of the crystal structures of the MC compounds.

\section{Results and Discussion}

\section{Structural characterization}

Three types of the solvent-inclusion compounds were crystallized in this study. The first were ACTN[X]-compounds prepared via the vapor exposure method presented in Fig. S1a, since the MC exhibits deliquescent nature to the ACTN vapor. Three other compounds, $\mathrm{MeOH}[\mathrm{Cl}]$ - and DCM[X]-compounds, were prepared via the precipitation method shown in Fig. S1b. When using $\mathrm{Cs}_{2}\left[\mathrm{Mo}_{6} \mathrm{Cl}_{14}\right]$ as precursor, we successfully obtained single crystals of the ACTN[Cl]-, $\mathrm{MeOH}[\mathrm{Cl}]$ - and DCM[Cl]-compounds and their crystal structures were characterized by SCXRD at 213 K. We also prepared the ACTN[Br]- and DCM[Br]-compounds using $\mathrm{Cs}_{2}\left[\mathrm{Mo}_{6} \mathrm{Br}_{14}\right]$ as precursor, of which structures were analyzed at $150 \mathrm{~K}$.

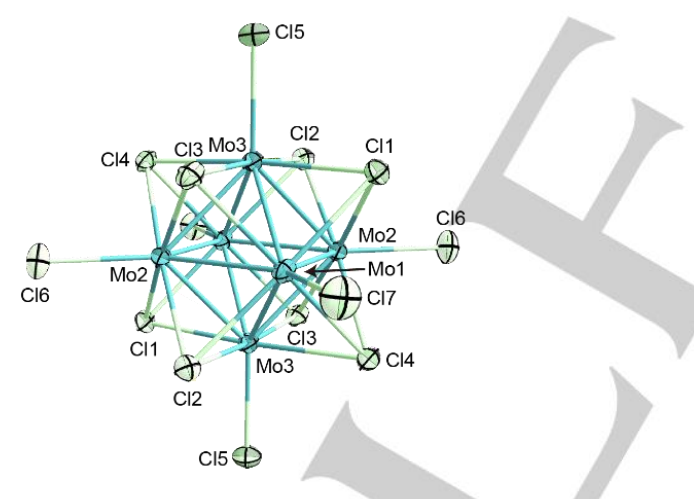

Figure 1. Representation of the discrete $\left[\mathrm{Mo}_{6} \mathrm{Cl}_{14}\right]^{2-}$ unit in the $\mathrm{ACTN}[\mathrm{Cl}]-$ compound refined at $213 \mathrm{~K}$. Atomic displacement ellipsoids are drawn at $50 \%$ probability level.

Figure 1 shows the discrete $\left[\mathrm{Mo}_{6} \mathrm{Cl}_{14}\right]^{2-}$ unit refined by SCXRD measurements. The MC compounds possess a wide-band gap ranged in 1.7-2.6 eV $\mathrm{eV}^{30}$ depending on the halogen atom of $X^{\prime} \mathrm{s}$ and $X^{a} S$, and the electronic feature is insensitive to changes in their packing arrangement. Indeed, as shown in Fig. S2, appearance of the all chlorine crystals showed translucent yellow colors similar to that of the precursor compound, $\mathrm{Cs}_{2}\left[\mathrm{Mo}_{6} \mathrm{Cl}_{14}\right]$.

However, the obtained crystals showed a very significant difference compared to the precursor compound, in that they rapidly deliquesce in air. It should be noted that we applied various analyses, including thermogravimetric (TG) analysis and thermal desorption analysis (TDS) utilizing mass spectrometry, but we could not obtain reliable results as samples degraded during the transfer from the preparation chamber to the analytical instruments. The FT-IR spectra of the degraded samples stored under vacuum for $5 \mathrm{~h}$ provide clear evidence of the presence of the solvent residues, as shown in Fig. S3. This indicates that part of the solvent molecules immobilized in the single crystals desorbed. Thus, the obtained solvent-inclusion crystals were unstable in air and under vacuum due to desorption of the inserted solvent molecules.

Table 1 shows the lattice parameters of the ACTN[X]-, DCM[X]and $\mathrm{MeOH}[\mathrm{Cl}]$-compounds. As a result of indexing the reflection data, we determined that the $\mathrm{ACTN}[\mathrm{X}]-$ and $\mathrm{MeOH}[\mathrm{Cl}]$ compounds crystallized in triclinic $P^{\overline{1}}$ space group, while the $\mathrm{DCM}[\mathrm{X}]$-compounds crystallized in tetragonal $P 4 / m n c$ space group. Thus, they are so-called pseudopolymorphs. ${ }^{31}$ The observed volume per formula unit $(V / Z)$ is all significantly larger than that of the trigonal-phase precursors as observed at room temperature. ${ }^{32,33}$ Structure refinement of every compound successfully converged since resulting in sufficiently small $R$ factor $(3-7 \%)$, while a little bit electrons resides still remained around the $\mathrm{MC}$ in the refinement of the $\mathrm{MeOH}[\mathrm{Cl}]$-compound.

Interatomic distances and crystallographic parameters (atomic coordinates, occupancy and atomic displacement parameters) of these solvent-inclusion compounds are summarized in Tables 2 and S1, respectively. The refined Mo-Mo and Mo-X interatomic distances of the $\left[\mathrm{Mo}_{6} \mathrm{X}_{14}\right]^{2-}$ cluster unit are insensitive to changes in the coordination environment. As listed in Table 2, the average Mo-Mo, Mo- $X^{i}$ and Mo- $X^{a}$ distances observed from every compound are very close to those found in the MC compounds that do not contain the guest molecule. ${ }^{34}$ This shows that the structure of $\left[\mathrm{Mo}_{6} \mathrm{X}_{14}\right]^{2-}$ is weakly affected by the insertion of the solvent molecules. It is assumable that the electronic orbital hybridization between the MC and guest molecule is very weak, because charge neutrality is retained in the compound system by the compensation between negatively charged MC and counter $\mathrm{Cs}^{+}$cations. This means that their packing arrangement varied to allow the solvent molecule to be inserted, while strong ionicities of the $\mathrm{MC}$ and $\mathrm{Cs}^{+}$cations $^{30}$ are retained. Since both the chlorine and bromine compounds resulted in the isostructural phases, hereafter we particularly focus on the characterization of the chlorine compounds.

Table 1. Crystallographic data and refined results from single crystal XRD for ACTN[Cl]-, DCM[Cl]-, MeOH[Cl]-, ACTN[Br]- and DCM[Br]-compounds.

\begin{tabular}{|c|c|c|c|c|c|}
\hline Structural formula & $\begin{array}{l}\mathrm{CsMO}_{3} \mathrm{Cl}_{7} \\
\cdot 3 \mathrm{C}_{3} \mathrm{H}_{6} \mathrm{O}\end{array}$ & $\begin{array}{l}\mathrm{CsMo}_{3} \mathrm{Cl}_{7} \\
\cdot 2 \mathrm{CH}_{2} \mathrm{Cl}_{2}\end{array}$ & $\begin{array}{l}\mathrm{Cs}_{2} \mathrm{Mo}_{6} \mathrm{Cl}_{14} \\
\cdot 3 \mathrm{CH}_{3} \mathrm{OH}\end{array}$ & $\begin{array}{l}\mathrm{CsMO}_{3} \mathrm{Br}_{7} \\
\cdot{ }_{3} \mathrm{C}_{3} \mathrm{H}_{6} \mathrm{O}\end{array}$ & $\begin{array}{l}\mathrm{CsMo}_{3} \mathrm{Br}_{7} \\
\cdot 2 \mathrm{CH}_{2} \mathrm{Cl}_{2}\end{array}$ \\
\hline $\begin{array}{l}\text { Formula weight } \\
/ \mathrm{g} \mathrm{mol}^{-1}\end{array}$ & 843.11 & 838.73 & 1421.79 & 1154.34 & 1150.00 \\
\hline Space group; $Z$ & $P \overline{1} ; 2$ & P4/mnc; 4 & $P \overline{1} ; 1$ & $P \overline{1} ; 2$ & P4/mnc; 4 \\
\hline Temperature / $\mathrm{K}$ & $213(2)$ & $213(2)$ & $213(2)$ & 150 (2) & 150 (2) \\
\hline Crystal system & Triclinic & Tetragonal & Triclinic & Triclinic & Tetragonal \\
\hline
\end{tabular}




\begin{tabular}{|c|c|c|c|c|c|}
\hline$a / \AA$ & $9.6978(2)$ & $9.1579(2)$ & $9.1144(5)$ & $9.9348(7)$ & $9.5388(5)$ \\
\hline$b / \AA$ & $10.9559(2)$ & & $11.7378(7)$ & $10.8592(8)$ & \\
\hline$c / \AA$ & $11.6545(3)$ & $21.3940(6)$ & $14.1990(9)$ & $12.1299(9)$ & $21.286(1)$ \\
\hline$\alpha /{ }^{\circ}$ & $93.450(1)$ & & $88.701(2)$ & $93.176(3)$ & \\
\hline$\beta /{ }^{\circ}$ & $107.521(1)$ & & $77.149(2)$ & 107.138(2) & \\
\hline$\gamma^{10}$ & $95.121(1)$ & & $73.444(2)$ & $94.630(2)$ & \\
\hline$V / \dot{A}^{3}$ & $1171.16(4)$ & $1794.25(9)$ & $1418.3(2)$ & 1242.1(2) & $1936.8(2)$ \\
\hline$\lambda(\mathrm{MoK \alpha}) / \AA$ & 0.71073 & & & & \\
\hline$R$ (int) & 0.0281 & 0.0386 & 0.0303 & 0.0559 & 0.0692 \\
\hline $\begin{array}{l}\text { Goodness-of-fit } \\
\text { on } F^{2}\end{array}$ & 1.168 & 1.359 & 1.034 & 1.080 & 1.229 \\
\hline $\begin{array}{l}\text { Final R-indexes } \\
(\triangleright 2 \sigma)\end{array}$ & $\begin{array}{l}R_{1}=0.0261 \\
w R_{2}=0.0617\end{array}$ & $\begin{array}{l}R_{1}=0.0506 \\
w R_{2}=0.1170\end{array}$ & $\begin{array}{l}R_{1}=0.0664 ; \\
W R_{2}=0.1502\end{array}$ & $\begin{array}{l}R_{1}=0.0268 \\
w R_{2}=0.0567\end{array}$ & $\begin{array}{l}R_{1}=0.0315 \\
\mathrm{w} R_{2}=0.0724\end{array}$ \\
\hline $\begin{array}{l}\text { Final R-indexes } \\
\text { (all data) }\end{array}$ & $\begin{array}{l}R_{1}=0.0318 \\
W R_{2}=0.0656\end{array}$ & $\begin{array}{l}R_{1}=0.0526 \\
w R_{2}=0.1195\end{array}$ & $\begin{array}{l}R_{1}=0.0701 \\
w R_{2}=0.1519\end{array}$ & $\begin{array}{l}R_{1}=0.0315 ; \\
w R_{2}=0.0584\end{array}$ & $\begin{array}{l}R_{1}=0.0367 \\
\mathrm{w} R_{2}=0.0761\end{array}$ \\
\hline $\begin{array}{l}\text { Largest difference } \\
\text { / e } \AA^{-3}\end{array}$ & $\begin{array}{l}0.774 \text { and } \\
-1.028\end{array}$ & $\begin{array}{l}2.601 \text { and } \\
-1.935\end{array}$ & $\begin{array}{l}2.950 \text { and } \\
-2.007\end{array}$ & $\begin{array}{l}1.682 \text { and } \\
-1.162\end{array}$ & $\begin{array}{l}1.069 \text { and } \\
-1.465\end{array}$ \\
\hline
\end{tabular}

\section{ACTN-compound}

Detailed crystal and coordination environments of the solventinclusion compounds are displayed in Figs. 2 and S4. The crystal structure of the ACTN[Cl]-compound displayed in Fig. 2a shows that the six ACTN molecules involved per MC unit are arranged around a pair of $\mathrm{Cs}^{+}$cations in order to reduce the Cs...O distances. In the unit cell, the ACTN molecules are located at general positions with every bond length being in agreement with the values for discrete molecules. ${ }^{35}$ While relatively high atomic displacement parameters were observed in the $\mathrm{C}$ and $\mathrm{O}$ atoms of the ACTN molecules, we did not find any splitting disorder for these elements. As shown in Fig. $2 \mathrm{a}$, each $\mathrm{Cs}^{+}$cation is tetrahedrally coordinated by four ACTN molecules via the oxygen atom of the $\mathrm{C}=\mathrm{O}$ group, with the $\mathrm{O} 2$ atoms being shared between two adjacent $\mathrm{Cs}^{+}$cations. The octahedral environment of the $\mathrm{Cs}^{+}$ cation is completed by two apical ligands ( $\mathrm{Cl} 5$ and $\mathrm{Cl} 7$ ). From Table 2 it could be noted that atomic distances between the $\mathrm{Cs}^{+}$ cations and $\mathrm{O}$ atoms of the ACTN molecules range from 3.011(4) to 3.097(4) $\AA$ in ACTN[Cl]-compound. These Cs ... O distances are identical to the sum of the ionic radii of the $\mathrm{Cs}^{+}(1.69 \AA)^{36}$ and $\mathrm{O}^{2-}$ ions $(1.40 \AA)^{37}$ whatever the nature of the ligands. It suggests that the ACTN molecules inserted into the lattice are stabilized by electrostatic interactions between the $\mathrm{Cs}^{+}$cations and the negatively charged $\mathrm{O}$ atoms of the $\mathrm{C}=\mathrm{O}$ groups.

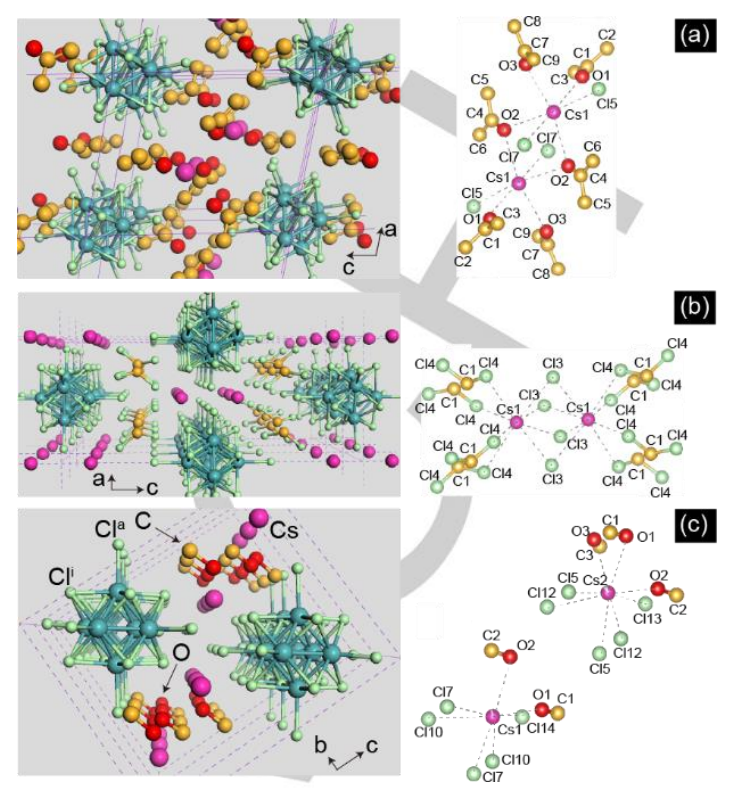

Figure 2. Crystal structures representation of (a) ACTN[Cl]-, (b) DCM[Cl] - and (c) $\mathrm{MeOH}[\mathrm{Cl}]$-compounds. Hydrogen atoms were omitted for clarity.

\section{DCM-compound}

The DCM[Cl]-compound evidences a layered structure, as shown in Fig. $2 b$, formed by the alternately stacking along the $c$-axis of the layer composed of the $\mathrm{Cs}^{+}$cations and cluster units with a layer composed of DCM molecules. In the crystal structure, four $\mathrm{Cl}$ atoms from the DCM molecules located on a $16 \mathrm{i}$ site $(\mathrm{Cl} 4)$, together with four $\mathrm{Cl}^{\mathrm{a} S}$ located on an $8 \mathrm{~h}$ site $(\mathrm{Cl} 3)$, surround the $\mathrm{Cs}^{+}$cation which is centered on a four-fold axis (C4). The MC unit is also positioned on the $\mathrm{C} 4$ axis so that two $\mathrm{Cl}^{\mathrm{a}} \mathrm{s}$ are aligned parallel to the main axis $(\mathrm{Cl} 2)$. We hypothesize that the layered structure of the $\mathrm{DCM}[\mathrm{Cl}]$-compound reduces the repulsive forces between the $\mathrm{Cl}^{-}$anions of the $\mathrm{MC}$ and $\mathrm{Cl}$ atoms of the DCM molecules and between the $\mathrm{Cs}^{+}$cations and the hydrogens of the DCM molecule. The interatomic distances between the $\mathrm{Cs}^{+}$ cations and $\mathrm{Cl}$ atoms of the DCMs, reported in Table 2, are longer than that encountered between the $\mathrm{Cs}^{+}$cations and $\mathrm{Cl}^{\mathrm{a}}$ ligands of the MC. This is explained by the reduced polarity of the chlorine functional groups of the DCM molecule compared to that of $\mathrm{Cl}^{\mathrm{a}}$.

\section{MeOH-compound}

The structure of the $\mathrm{MeOH}[\mathrm{Cl}]-$ compound is shown in Fig. 2c. It is noticeable that some small electron residues $\left(\approx 2.95\right.$ e $\left.\AA^{-3}\right)$ remained very close to the Mo sites due to low crystallinity, while the refined $R$-factor $\left(R_{1}=6.64 \%\right)$ was significantly small as seen in Table 1. Thus, we could not fully refine the positions of the protons, but this information is complemented by the theoretical calculation represented below. With the cationic sites, the Cs sites are splitted into three sites along the a-axis. Occupation at one of the splitting sites was close to $90 \%$, while those for the others were a few $\%$. Hence, the sum of the occupation was very close to unity. This suggests that the formation of $\mathrm{MeO}^{-}$by reaction of $\mathrm{MeOH}$ and the cluster unit must be excluded. 
In the unit cell of the $\mathrm{MeOH}[\mathrm{Cl}]$-compound, six $\mathrm{MeOH}$ molecules fully occupy the interstices between four $\mathrm{Cs}^{+}$cations, and accordingly three $\mathrm{MeOH}$ molecules locate per $\mathrm{MC}$ unit $(Z=$ 2). Two asymmetric $\mathrm{MeOH}$ molecules over the three contained in the unit cell are shared by the two $\mathrm{Cs}^{+}$cations, and the other one is simply intercalated with being interacted with only the Cs2 site, as shown in Fig. 2c. While the intercalated $\mathrm{MeOH}$ molecules coordinate to the $\mathrm{Cs}^{+}$cations, a characteristic feature of the $\mathrm{MeOH}[\mathrm{Cl}]$-compound is the relatively long $\mathrm{Cs} \cdots \mathrm{Cl}$ distances shown in Table 2. While two $\mathrm{Cl}^{\mathrm{a}} \mathrm{s}$ coordinate to a $\mathrm{Cs}^{+}$cation in the ACTN[Cl]-compound, five $\mathrm{Cl}^{\mathrm{a}} \mathrm{S}$ coordinate to $\mathrm{a} \mathrm{Cs}^{+}$cation in the $\mathrm{MeOH}[\mathrm{Cl}]$-compound, as shown in Fig. 2c. This higher coordination number could explain the relatively longer $\mathrm{Cs} \cdots \mathrm{Cl}^{\mathrm{a}}$ distances. In addition, the Cs...O distances in the $\mathrm{MeOH}[\mathrm{Cl}]$ compound were longer than those encountered in the ACTN[CI]compound. Indeed, the distances between highly occupied Cs sites (Cs1 and Cs2) and the $\mathrm{O}$ atoms of the $\mathrm{MeOH}$ molecules ranged from 3.069(19) to $3.400(17) \AA$, as shown in Table 2, with some of them being significantly longer than the combined ionic radii of $\mathrm{Cs}^{+}$and $\mathrm{O}^{2-}$. We suppose that the repulsive force between the hydrogen of the $\mathrm{MeOH}$ molecule and the $\mathrm{Cs}^{+}$cation is one reason for the relatively long Cs...O distance in the $\mathrm{MeOH}[\mathrm{Cl}]-$ compound.

Table 2. Selective interatomic distances $(/ \mathrm{A})$ for $A C T N[C l]-$, ACTN[Br]-, $\mathrm{DCM}[\mathrm{Cl}]-$, DCM[Br]-, and $\mathrm{MeOH}[\mathrm{Cl}]-\mathrm{compounds}$.

\begin{tabular}{|c|c|c|}
\hline & $\mathrm{ACTN}[\mathrm{Cl}]$ & $\mathrm{ACTN}[\mathrm{Br}]$ \\
\hline Mo-Mo & $2.600(1)-2.607(1)$ & $2.634(1)-2.639(1)$ \\
\hline Mo- $X^{i}$ & $2.471(1)-2.478(1)$ & $2.595(1)-2.607(1)$ \\
\hline Mo- $X^{a}$ & $2.421(1)-2.437(1)$ & $2.591(1)-2.608(1)$ \\
\hline Cs $\cdots O$ & $3.011(4)-3.097(4)$ & $2.999(4)-3.079(3)$ \\
\hline$C s \cdots X^{a}$ & $3.520(1), 3.649(1)$ & $3.635(1), 3.783(1)$ \\
\hline C-C & $1.475(7)-1.490(7)$ & $1.486(8)-1.501(6)$ \\
\hline \multirow[t]{2}{*}{$\mathrm{C}=\mathrm{O}$} & $1.202(6)-1.210(5)$ & $1.204(6)-1.212(6)$ \\
\hline & $\mathrm{DCM}[\mathrm{Cl}]$ & $\mathrm{DCM}[\mathrm{Br}]$ \\
\hline Mo-Mo & $2.605(1), 2.611(1)$ & $2.636(1), 2.642(1)$ \\
\hline Mo-Xi & $2.470(1)-2.472(1)$ & $2.593(1)-2.598(1)$ \\
\hline Mo- $X^{a}$ & $2.443(1), 2$ & $2.599(1), 2.603(2)$ \\
\hline Cs $\cdots X^{a}$ & $3.486(1)$ & $3.651(1)$ \\
\hline Cs $\cdots \mathrm{Cl}$ (of DCM) & $3.570(1)$ & $3.611(2)$ \\
\hline \multirow[t]{2}{*}{$\mathrm{C}-\mathrm{Cl}$ (of DCM) } & $1.765(4)$ & $1.759(7)$ \\
\hline & $\mathrm{MeOH}[\mathrm{Cl}]$ & \\
\hline Mo-Mo & $2.596(2)-2.616(2)$ & \\
\hline Mo-Cli & $2.454(3)-2.484(3)$ & \\
\hline $\mathrm{Mo}-\mathrm{Cl}^{\mathrm{a}}$ & $2.429(4)-2.448(4)$ & \\
\hline
\end{tabular}

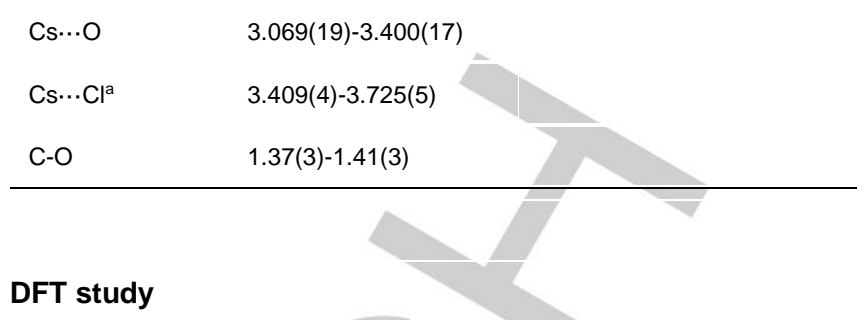

Density functional theory calculations were performed to examine the structural and electronic characteristics of the solventinclusion compounds $(\mathrm{X}=\mathrm{Cl}, \mathrm{Br}, \mathrm{I})$ systematically with respect to the halogen ligands. Performing the structural relaxation of the compounds using the conventional unit cell determined by SCXRD as the initial structural model, we did not consider any superlattice models although the $\mathrm{MeOH}[\mathrm{X}]$-compounds exhibit a splitting of the Cs sites. This is because the superlattice model that reproduces the disorder of the Cs sites found in the $\mathrm{MeOH}[\mathrm{Cl}]$-compound requires very large computational cost to obtain good convergence in the structural relaxation. Even while applying such simplified structural models, we obtained excellent convergence of most structural relaxation calculations performed in this study except the $\mathrm{MeOH}[\mathrm{Br}]$-compound. The incomplete convergence of the $\mathrm{MeOH}[\mathrm{Br}]$-compound was possibly due to the too simplified structural model and still requirement for especially large computational resources. In following discussion, we examine whether DFT can approximate structural and electronic features of the solvent-inclusion compounds.

The relaxed lattice parameters of the solvent-inclusion compounds are summarized in Table S2. A comparison between the observed and calculated lattice parameters shown in Tables 1 and S2, respectively, suggests that DFT overestimates the unit cell volumes so that the difference between observed and calculated volumes is $7.9 \%$ for $\mathrm{ACTN}[\mathrm{Cl}], 3.0 \%$ for $\mathrm{MeOH}[\mathrm{Cl}]$, $4.6 \%$ for $\mathrm{DCM}[\mathrm{Cl}], 12.1 \%$ for ACTN[Br], and $5.6 \%$ for DCM[Br]. These are a typical tendency of $\mathrm{GGA},{ }^{38}$ as already reported in a similar level with the overestimated unit cell volumes of $\mathrm{Cs}_{2}\left[\mathrm{Mo}_{6} \mathrm{X}_{14}\right]^{30,33}$ Some representative interatomic distances and bond angles of the relaxed structures are shown in Table S3, which were very consistent to those deduced from the SCXRD measurements. Hence, these results indicate that GGA could precisely approximate the atomic positions of the solventinclusion compounds. Table S4 summarizes standard formation enthalpy of the solvent-inclusion compounds calculated from the difference between their total energy and summation of the total energies of $\mathrm{Cs}_{2}\left[\mathrm{Mo}_{6} \mathrm{X}_{14}\right]$ and corresponding solvent molecules. Table S4 shows that every formation enthalpy resulted in a negative value, indicating that insertion of the guest molecules into the $\mathrm{Cs}_{2}\left[\mathrm{Mo}_{6} \mathrm{X}_{14}\right]$ lattices is exothermic. Hence, the reaction where the $\mathrm{Cs}_{2}\left[\mathrm{Mo}_{6} \mathrm{X}_{14}\right]$ solids absorb the gaseous solvent under sufficient vapor pressure will naturally proceed at zero temperature. Table S4 also shows that the formation enthalpy of the ACTN $[X]$-compounds were much lower than that of the others, being consistent to the fact that $\mathrm{Cs}_{2}\left[\mathrm{Mo}_{6} \mathrm{X}_{14}\right]$ specially absorbed the ACTN vapor. As comparison among the formation enthalpy values of the three halide compounds, the values were slightly decreased in the order of $\mathrm{I}>\mathrm{Br}>\mathrm{Cl}$. This is an indication that the solvent molecules are stabilized particularly in the chloride lattice 
because strong ionicity of $\left[\mathrm{Mo}_{6} \mathrm{Cl}_{14}\right]^{2-}$ stabilizes the interaction of the solvent molecules.

The result of the effective charge analysis is shown in Table S5. As seen from this table, the charges of Mo, $X^{i}$ and $X^{a}$ varied little among three solvent-inclusion compounds. This result supports that incorporation with the solvent little affects the electronic states of the MCs. It is noteworthy that the total atomic charge of the inserted solvent molecules calculated by HPA was -0.06 for ACTN, -0.11 for $\mathrm{MeOH}$ and 0.03 for $\mathrm{DCM}$, which suggests that ACTN and DCM behave as neutral molecules in the lattice, in contrast that $\mathrm{MeOH}$ seemed to have slightly negative charge, probably related to the strong polar characteristics of the $\mathrm{O}$ atom. Simultaneously, $\mathrm{MeOH}$ exhibits relatively high positive charge of the $\mathrm{H}$ atom belonging to the $\mathrm{OH}$ group. The electron density distribution around $\mathrm{MeOH}$ in the chlorine compound shown in Fig. 3 indicates that the electronic hybridization between the $\mathrm{Cl}^{\mathrm{a}}$ and $\mathrm{H}$ atoms is small. On the other hand, the calculated hydrogen bond lengths of $(\mathrm{O} 2) \mathrm{H} \cdots \mathrm{Cl} 12$ and $(\mathrm{O} 3) \mathrm{H} \cdots \mathrm{Cl} 14$ in the $\mathrm{MeOH}[\mathrm{Cl}]-$ compound ranged 2.15-2.26 $\AA$, which is well matched with the typical hydrogen bond length between $\mathrm{Cl}$ and $\mathrm{H}$ atoms. ${ }^{39}$ In previous study, it was presumed that the water molecule in $\mathrm{Cs}_{2}\left[\mathrm{Mo}_{6} \mathrm{X}_{14}\right] \cdot \mathrm{H}_{2} \mathrm{O}$ binds with $\mathrm{X}^{\mathrm{a}}$ of $\left[\mathrm{Mo}_{6} \mathrm{X}_{14}\right]^{2-}$ through the hydrogen bonding and thermal vibrations whereas DFT indicates small density overlap between the water molecule and MC unit. ${ }^{40}$ It is assumable that analogous interaction between the $\mathrm{MC}$ unit and $\mathrm{OH}$ group should be involved in the $\mathrm{MeOH}[\mathrm{X}]$-compounds considering that the calculated interatomic distances and electronic charge features of $\mathrm{MeOH}$ are similar to those of the water molecule in $\mathrm{Cs}_{2}\left[\mathrm{Mo}_{6} \mathrm{X}_{14}\right] \cdot \mathrm{H}_{2} \mathrm{O}$.

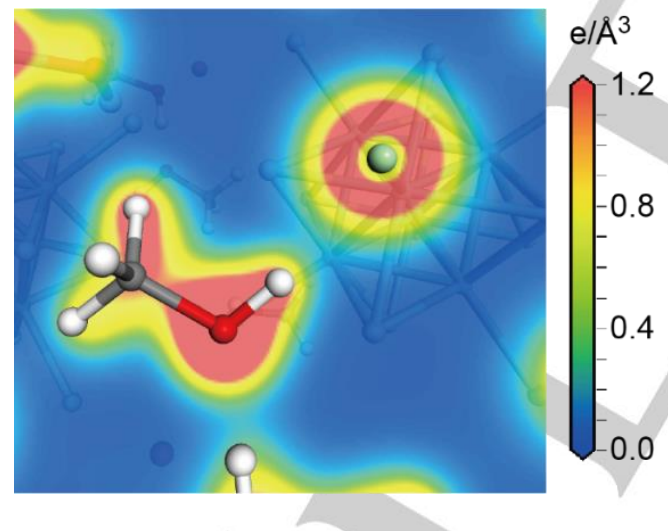

Figure 3. Electron density distribution around the $\mathrm{MeOH}$ molecule intercalated upon the $\mathrm{MeOH}[\mathrm{Cl}]$-compound.

For further understanding of the electronic properties of the solvent-inclusion compounds, we discuss their projected density of states (PDOSs) plotted in Fig. 4. In this figure, the Fermi level of every compound is shifted to $0 \mathrm{eV}$. The figure shows that the electronic states of the MCs (namely PDOSs of Mo and X) located over the valence and conduction bands (VBs and CBs) appear to be very similar among the three solvent inclusion. The band gap was calculated to be $2.4 \mathrm{eV}$ for $\mathrm{X}=\mathrm{Cl}, 2.2 \mathrm{eV}$ for $\mathrm{X}=\mathrm{Br}$ and 1.8 $\mathrm{eV}$ for $\mathrm{X}=\mathrm{I}$, which is also a little varied regardless of the molecule specimen, and these values are close to those of $\mathrm{Cs}_{2}\left[\mathrm{Mo}_{6} \mathrm{X}_{14}\right] .^{30}$ These results evidence that the electronic states of the MCs are fairly isolated from the solvent molecules. As the electronic structures of $\mathrm{MeOH}$ and $\mathrm{DCM}$ lie far from the valence band maximum (VBM) and conduction band minimum (CBM), they do not affect absorption and excitation nature of the MCs. In contrast, the $\mathrm{O} 2 p$ and $\mathrm{C} 2 p$ states of the ACTN[X]-compounds, corresponding to a lone pair of the $\mathrm{O}$ atom and bonding $\pi$ orbital of the $\mathrm{C}=\mathrm{O}$ group, respectively, are formed near the VBM. The electronic states attributed to the ACTN molecule were located nearer to the VBM in the lighter-halogen compounds. The electronic states of the MCs should be located at lower level with the electronegativity of $\mathrm{X}$, and then the relative energy position between the MC and ACTN become closer. The presence of the extra electronic states close to the VBM would involve a transition probability of a non-radiative decay during the excitation, leading to inhibition in the optical performances of the MC compounds.

\section{General discussion}

As indicated by above analyses, the ACTN, $\mathrm{MeOH}$ and DCM molecules can be co-crystallized with $\mathrm{Cs}^{+}$and $\left[\mathrm{Mo}_{6} \mathrm{X}_{14}\right]^{2-}$ using $\mathrm{Cs}_{2}\left[\mathrm{Mo}_{6} \mathrm{X}_{14}\right]$ cluster compounds. The inclusion number of the solvent molecules per MC unit resulted in 1:6 for ACTN, 1:3 for $\mathrm{MeOH}$ and 1:4 for DCM. The inclusion number of solvent molecules will differ depending on the cationic specimen, since Johnston et al. have recently reported that $\left[\mathrm{Mo}_{6} \mathrm{Cl}_{14}\right]^{2-} \mathrm{co}-$ crystallizes with three ACTN molecules that is trapped by a counter $p$-phenylenediammonium cation via the hydrogen bonding. ${ }^{41}$ As the mononuclear complexes typically contain 1:1 2 solvent molecules in their crystal structure, ${ }^{7,42}$ the MCs are considered to include a large number of molecules. Among the obtained compounds, inclusion of $\mathrm{ACTN}$ and $\mathrm{MeOH}$ results in low symmetry packing (space group $P \overline{1}$ ), which is rationalized assuming that these polar solvents interact with both $\mathrm{MC}$ and $\mathrm{Cs}^{+}$ cations. Indeed, the DFT calculations suggest that these solvent molecules are stabilized as their polar element electrostatically interacts with the $\mathrm{Cs}^{+}$cation. In addition, $\mathrm{MeOH}$ is specially bounded with the $\mathrm{MC}$ via the hydrogen bonding between $\mathrm{X}^{\mathrm{a}}$ atom of $\mathrm{MC}$ and $\mathrm{H}$ atom of the $\mathrm{OH}$ group. As a result, the incorporation of $\mathrm{MeOH}$ and ACTN is considered to restrict the conformational degree of the MCs, giving the crystallization of triclinic phases. Nevertheless, the centrosymmetric feature remained in every composition possibly due to the difficulty to break the centrosymmetry of the MCs that originally favor the $\mathrm{O}_{\mathrm{h}}$ point group symmetry. ${ }^{43}$ In the previous literature, ${ }^{44,45} \mathrm{MC}$ compounds also trap solvent molecules by counter cations as ours, and they do not oppose the nature of centrosymmetry. In order to construct the asymmetric structures for functionalizing the MC compounds in optics and optoelectronics, we hypothesized that incorporation of guest molecules further strongly interacted with the MCs and/or having strong hyperpolarizability will be needed. In addition, the present solvent-inclusion compounds were not stable so much under the ambient conditions, and then detailed property exploration is strongly limited. The structural stability will also be improved by the incorporation of less volatile molecules. As the molecular size and affinity with the guest molecules are tunable by the ligand exchange of the MCs, in the future we will address 
to co-crystallize MCs and larger organic guest components with attractive optical features to exploit the potential functionalities of the MC compounds.

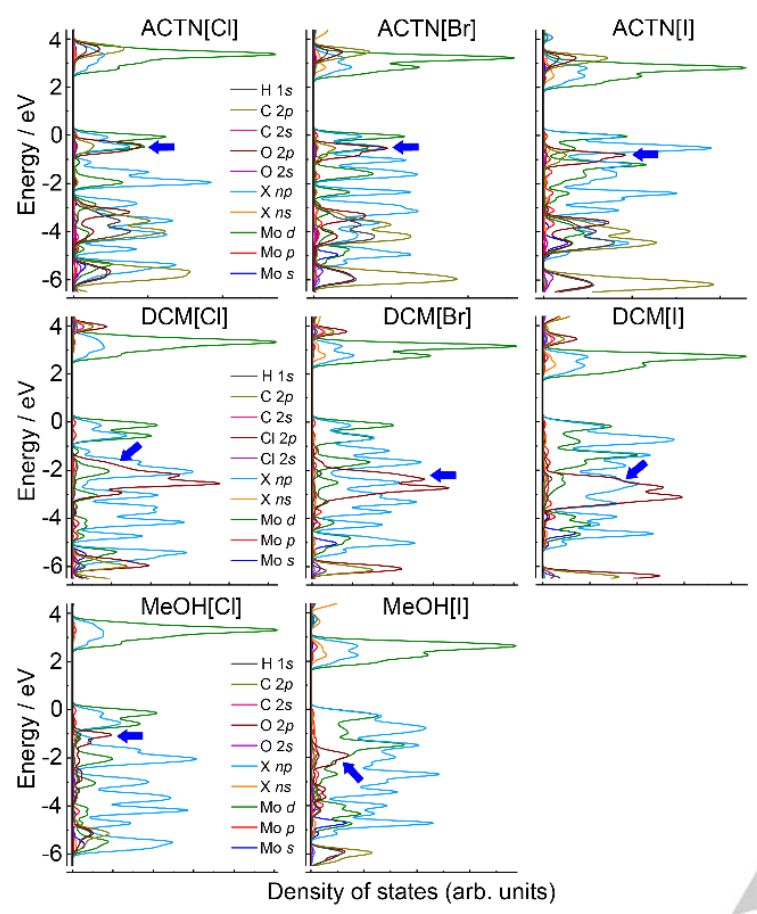

Figure 4. Projected density of states (PDOSs) of the solvent-inclusion compounds. Arrows mean energy band position attributed to the inserted solvent molecules.

\section{Conclusions}

In this study, we have obtained three types of metal cluster (MC) compounds containing high concentration of solvent molecules: $\mathrm{MeOH}[\mathrm{Cl}]$-compound ( $\left.P^{\overline{1}}\right), \operatorname{ACTN}[\mathrm{X}]$-compounds $\left(P_{\overline{1}}\right)$, and $\mathrm{DCM}[\mathrm{X}]$-compounds $(P 4 / m n c)$ with $\mathrm{X}=\mathrm{Cl}$ or $\mathrm{Br}$. Their crystal structures were determined from single-crystal XRD data. All the crystal structures are stabilized by reducing the interatomic distances between $\mathrm{Cs}^{+}$cations and negatively polarized atoms in the solvent molecules in order to decrease the electrostatic potential. The DFT studies suggest that the $\mathrm{MeOH}$ molecule is bound not only to the $\mathrm{Cs}^{+}$cations with electrostatic interactions but also to the MC unit through hydrogen bonding, which leads to structural disorder in the $\mathrm{MeOH}[\mathrm{Cl}]$-compound. While crystallographically non-centrosymmetric solids are interesting in terms of optoelectronic properties, all new compounds found in this study keep centrosymmetric crystal structure even though the insertion of the guest solvent molecule. On the other hand, it is worth to point out that the volumetric densities of the solvent molecules in the solvent-inclusion compounds are very high compared to that of the typical mononuclear metal complexes. As the chemical characteristics of the MC unit can be tuned by the ligand and counter cation substitution, we expect that cocrystallization with diverse guest solvent molecules and improvement of the chemical stability will be possible by optimizing their chemical compositions.

\section{Experimental Section}

Preparation of $\mathrm{Cs}_{2}\left[\mathrm{Mo}_{6} \mathrm{X}_{14}\right](\mathrm{X}=\mathrm{Cl}, \mathrm{Br})$ precursor: Two monohalogenated compounds, $\mathrm{Cs}_{2}\left[\mathrm{Mo}_{6} \mathrm{X}_{14}\right](\mathrm{X}=\mathrm{Cl}, \mathrm{Br})$, were synthesized by solid-state chemistry or by combining solid state and solution chemistries. For the synthesis of $\mathrm{Cs}_{2}\left[\mathrm{Mo}_{6} \mathrm{Cl}_{14}\right]$, we employed a derivative method reported by Healy. ${ }^{46}$ In this method, we used the single crystal of $\left(\mathrm{H}_{3} \mathrm{O}\right)_{2}\left[\mathrm{Mo}_{6} \mathrm{Cl}_{14}\right] \cdot 7 \mathrm{H}_{2} \mathrm{O}$ as the precursor and we performed the cation exchange from $\mathrm{H}_{3} \mathrm{O}^{+}$to $\mathrm{Cs}^{+}$by addition of $\mathrm{CsCl}$ into the precursordissolved ethanol. For the synthesis of $\mathrm{Cs}_{2}\left[\mathrm{Mo}_{6} \mathrm{Br}_{14}\right]$, we prepared this compound by heating a mixture of $\mathrm{CsBr}$ and $\mathrm{MoBr}_{2}$ at $800^{\circ} \mathrm{C}$ for more than $72 \mathrm{~h}$ sealed silica container. ${ }^{32}$ The obtained solids were dissolved into ACTN solvent for separation of byproducts by filtration and they were crystallized again with a rotatory evaporator. Detailed preparation methods of these precursors are described in the SI.

Vapor exposure method: The ACTN-inclusion compounds, $\mathrm{Cs}_{2}\left[\mathrm{Mo}_{6} \mathrm{X}_{14}\right] \cdot 6\left(\mathrm{CH}_{3} \mathrm{COCH}_{3}\right)(\mathrm{ACTN}[\mathrm{X}]$-compounds), were prepared using a vapor exposure method where the precursor powders were simply exposed to the vaporized solvent. We also confirmed that these compounds were crystallized using the usual slow evaporation method. The vapor exposure experiment was performed with an assembly of the glass vessels as shown in Fig. S1a. The $5-\mathrm{mg} \mathrm{Cs}_{2}\left[\mathrm{Mo}_{6} \mathrm{X}_{14}\right]$ precursors were placed on the bottom of the $5-\mathrm{mL}$ glass vessel, and this was placed in the $50-\mathrm{mL}$ one where $60-\mu \mathrm{L}$ acetone solvent was stored. This system was closed and kept at $25{ }^{\circ} \mathrm{C}$ for $24 \mathrm{~h}$. During this experiment, the precursor powders exhibited deliquescence in the ACTN vapor and single crystals were crystallized from the dissolved phase. All procedures were conducted in a glove box fulfilled with well-dried $\mathrm{N}_{2}$ gas (concentrations of $\mathrm{O}_{2}$ and $\mathrm{H}_{2} \mathrm{O}<0.1 \mathrm{ppm}$ ) to avoid the contamination from moisture.

Precipitation method: The precipitation method was used for synthesizing the MC compounds containing methanol (MeOH[Cl]compounds) or dichloromethane (DCM[X]-compounds). It was carried out using either $\mathrm{MeOH}$ or ACTN as solvent, and DCM as antisolvent. 3-mg $\mathrm{Cs}_{2}\left[\mathrm{Mo}_{6} \mathrm{X}_{14}\right]$ powders were dissolved into either $0.2-\mathrm{mL} \mathrm{MeOH}$ or ACTN and then the obtained solutions were put in the $5-\mathrm{mL}$ glass vessel. This was closed in the $50-\mathrm{mL}$ one where $5-\mathrm{mL}$ DCM was loaded as presented in Fig. S1b. While keeping this system at $25^{\circ} \mathrm{C}$ in the glovebox, the DCM solvent was gradually evaporated and diffused into the cluster solution, causing decrease of the compound solubility. As a result, single crystals were precipitated on the bottom of the inner vessel. These crystals were quickly collected by removal of the solvent.

Characterization and analysis: Fourier transform infrared spectroscopy (FT-IR) measurement was performed at room temperature using a Nicolet iS50 spectrometer (Thermo Scientific Co. Ltd.) with a diffuse reflectance setup. Before the measurement, the prepared crystals were retained in ultra-high-vacuum (UHV) chamber where the background pressure was kept less than $6.0 \times 10^{-10}$ torr for $5 \mathrm{~h}$. The sample was diluted by mixing with dried $\mathrm{KBr}$ powder in the weight ratio of sample: $\mathrm{KBr}=1: 20$. The crystal structures of the solvent-inclusion MC compounds were characterized by single-crystal X-ray diffraction (SCXRD). The SCXRD measurements of the chloride compounds were performed with a Saturn CCD diffractometer equipped with a VariMax confocal optics (Rigaku corp.) for monochromated MoKa $(\lambda=0.71073 \AA)$ radiation. The SCXRD measurements of the bromide compounds were performed with a D8 Venture Bruker AXS diffractometer also using the MoKa radiation. During the measurement, the sample temperatures were set at $213 \mathrm{~K}$ for the 
chlorides and $150 \mathrm{~K}$ for the bromides, using nitrogen gas to prevent desorption of the inserted solvent from the prepared crystals. In the structure refinement, all non-hydrogen atoms were refined with anisotropic atomic displacement parameters. The conditions of data collection and results of the structure refinements are summarized in Table 1. Further details can be referred in the SI.

Calculation: The structural and electronic properties of the solventinclusion MC compounds were investigated by density functional theory (DFT) calculations. In this study, we performed the DFT calculations of not only the chlorine and bromine compounds but also the iodine ones for systematic investigation. Initial structures of the iodine compounds were virtually created with the crystal structures refined in SCXRD. We adopted the revision of the generalized gradient approximation (GGA), PBESol, ${ }^{47}$ implemented in a plane-wave based pseudo-potential calculation code, the CASTEP code ${ }^{48}$ for this simulation study. Stable lattice parameters and atomic positions were obtained by geometry optimization calculations, and electronic charge of each element was approximated by means of the Hirshfeld ${ }^{49,50}$ population analysis (HPA). Detailed calculation method is described in the SI.

Crystallographic data: Further details of the crystal structure investigations can be obtained from the Cambridge Crystallographic Data Centre (CCDC), on quoting the deposit number 1847738 (for $\mathrm{Cs}_{2}\left[\mathrm{Mo}_{6} \mathrm{Cl}_{14}\right] \cdot 3 \mathrm{CH}_{3} \mathrm{OH}$ ), 1847736 (for $\mathrm{Cs}_{2}\left[\mathrm{Mo}_{6} \mathrm{Cl}_{14}\right] \cdot 6 \mathrm{CH}_{3} \mathrm{COCH}_{3}$ ), 1848250 (for $\mathrm{Cs}_{2}\left[\mathrm{Mo}_{6} \mathrm{Br}_{14}\right]$. $6 \mathrm{CH}_{3} \mathrm{COCH}_{3}$ ), 1847737 (for $\mathrm{Cs}_{2}\left[\mathrm{Mo}_{6} \mathrm{Cl}_{14}\right] \cdot 4 \mathrm{CH}_{2} \mathrm{Cl}_{2}$ ) and 1848251 (for $\mathrm{Cs} 2\left[\mathrm{Mo}_{6} \mathrm{Br}_{14}\right] \cdot 4 \mathrm{CH}_{2} \mathrm{Cl}_{2}$ ).

\section{Acknowledgements}

The majority of this work was carried out under the France-Japan international collaboration framework (UMI LINK). The authors thank those involved in LINK and its related activities, particularly David Lechevalier and Mari Kono of Saint-Gobain KK (Tokyo, Japan) for their contributions to the management of LINK, Noée Dumait and Serge Paofai of ISCR for their contributions to the synthesis of metal clusters precursors. N.S. would also like to thank Prof. Junzo Tanaka of Tokyo Tech for support and encouragement. P.L. and S.C. thank T. Roisnel and V. Dorcet of the CDIFX, Rennes, France, for their help during single crystal data collection. Parts of this study have been financially supported by NIMS, Saint-Gobain Company (Paris, France), Region Bretagne (France), CNRS, Rennes Univ. and Fondation Langlois. This study has been also supported by the Ministry of Education Science, Culture, Sports, Science and Technology via Elemental Strategy initiative (No. JPMXP0112101001).

Keywords: Cluster compounds $•$ Molybdenum $•$ Halides $•$ Ab initio calculations $\cdot$ Solid-state structures

[1] Y.-M. You, W.-Q. Liao, D. Zhao, H.-Y. Ye, Y. Zhang, Q. Zhou, X. Niu, J. Wang, P.-F. Li, D.-W. Fu, Z. Wang, S. Gao, K. Yang, J.-M. Liu, J. Li, Y. Yan, R.-G. Xiong, Science 2017, 357, 306-309.

[2] Z. Sun, X. Wang, J. Luo, S. Zhang, D. Yuan, M. Honga, J. Mater. Chem. C 2013, 1, 2561-2567.

[3] H. Furukawa, K. E. Cordova, M. O'Keeffe, O. M. Yaghi, Science 2013, 341,1230444

[4] T. R. Cook, Y.-R. Zheng, P. J. Stang, Chem. Rev. 2013, 113, 734-777.

[5] L. Chen, R. Luque, Y. Li, Chem. Soc. Rev. 2017, 46, 4614-4630.
[6] O. M. Yaghi, M. O'Keeffe, N. W. Ockwig, H. K. Chae, M. Eddaoudi, J. Kim, Nature 2003, 423, 705-714.

[7] F. Maharaj, V. Russell, H. Chow, M. Page, M. Scudder, D. Craig, I. Dance CrystEngComm 2003, 5, 285-293.

[8] D. V. Soldatov, G. D. Enright, J. A. Ripmeester, Chem. Mater. 2002, 14, 348-356.

[9] B. Chen, S. Xiang, G. Qian, Acc. Chem. Res. 2010, 43, 1115-1124.

[10] B. V. Voorde, B. Bueken, J. Denayer, D. D. Vos, Chem. Soc. Rev. 2014 43, 5766-5788.

[11] W. Yang, H.-Y. Wu, R.-X. Wang, Q.-J. Pan, Z.-M. Sun, H. Zhang, Inorg Chem. 2012, 51, 11458-11465.

[12] C. Eames, J. M. Frost, P. R. F. Barnes, B. C. O'Regan, A. Walsh, M. S. Islam, Nat. Commun. 2015, 6, 7497.

[13] J. M. Taylor, K. W. Dawson, G. K. H. Shimizu, J. Am. Chem. Soc. 2013, 135, 1193-1196.

[14] A. Pinkard, A. M. Champsaur, X. Roy, Acc. Chem. Res. 2018, 51, 919929.

[15] D. H. Fabini, C. C. Stoumpos, G. Laurita, A. Kaltzoglou, A. G. Kontos, P. Falaras, M. G. Kanatzidis, R. Seshadri, Angew.Chem. Int. Ed. 2016, 55, $15392-15396$

[16] F. A. Cotton, Inorg. Chem. 1964, 3, 1217-1220.

[17] J. R. Long, L. S. McCarty, R. H. Holm, J. Am. Chem. Soc. 1996, 118, 4603-4616.

[18] A. Perrin, C. Perrin, C. R. Chim. 2012, 15, 815-836.

[19] T. C. Zietlow, W. P. Schaefer, B. Sadeghi, N. Hua, H. B. Gray, Inorg Chem. 1986, 25, 2195-2198.

[20] B. G. Hughes, J. L. Meyer, P. B. Fleming, R. E. McCarley, Inorg. Chem. 1970, 9, 1343-1346.

[21] F. Ogliaro, S. Cordier, J.-F. Halet, C. Perrin, J.-Y. Saillard, M. Sergent, Inorg. Chem. 1998, 37, 6199-6207.

[22] A. W. Maverick, J. S. Najdzionek, D. MacKenzie, D. G. Nocera, H. G. Gray, J. Am. Chem. Soc. 1983, 105, 1878-1882.

[23] T. C. Zietlow, M. D. Hopkins, H. B. Gray, J. Solid State Chem. 1985, 57, $112-119$.

[24] G. Saito, H. Hosoda, Y. Yoshida, J. Hagiwara, K. Nishimura, H. Yamochi, A. Otsuka, T. Hiramatsu, Y. Shimazaki, K. Kirakci, S. Cordier, C. Perrin, J. Mater. Chem. 2012, 22, 19774-19791.

[25] T. Hiramatsu, Y. Yoshida, G. Saito, A. Otsuka, H. Yamochi, Y. Shimizu, Y. Hattori, Y. Nakamura, H. Kishida, H. Ito, K. Kirakci, S. Cordier, C. Perrin, J. Mater. Chem. C 2015, 3, 11046.

[26] P. Batail, C. Livage, S. S. P. Parkin, C. Coulon, J. D. Martin, E. Canadell, Angew. Chem. Int. Ed. Engl. 1991, 30, 1498-1500.

[27] A. Kuc, T. Heine, T. Mineva, Struct Chem 2012, 23, 1357-1367.

[28] H. Zhou, C. S. Day, A. Lachgar, Chem. Mater. 2004, 16, 4870-4877.

[29] Y. Rong, Z. Tang, Y. Zhao, X. Zhong, S. Venkatesan, H. Graham, M. Patton, Y. Jing, A. M. Guloy, Y. Yao, Nanoscale 2015, 7, 10595-10599.

[30] N. Saito, S. Cordier, P. Lemoine, T. Ohsawa, Y. Wada, F. Grasset, J. S. Cross, N. Ohashi, Inorg. Chem. 2017, 56, 6234-6243.

[31] A. Nangia, G. R. Desiraju, Chem. Commun. 1999, 605-606.

[32] K. Kirakci, S. Cordier, C. Perrin, Z. Anorg. Allg. Chem. 2005, 631, 411 416.

[33] N. Saito, Y. Wada, P. Lemoine, S. Cordier, F. Grasset, T. Ohsawa, N Saito, J. S. Cross, N. Ohashi, Jpn. J. Appl. Phys. 2016, 55, 075502-1-8.

[34] N. Saito, P. Lemoine, N. Dumait, M. Amela-Cortes, S. Paofai, T. Roisnel V. Nassif, F. Grasset, N. Ohashi, S. Cordier, J. Clust. Sci. 2017, 28, 773798.

[35] D.-W. Liao, A. M. Mebel, Y.-T. Chen, S.-H. Lin, J. Phys. Chem. A 1997, 101, 9925-9934

[36] Y. Marcus, J. Solution Chem. 1983, 12, 271-275.

[37] B. E. Conway, E. Ayranci, J. Solution Chem. 1999, 28, 163-192.

[38] P. Haas, F. Tran, P. Blaha, Phys. Rev. B 2009, 79, 085104-1-10.

[39] J.-H. Choi, K. T. Kuwata, Y.-B. Cao, M. Okumura, J. Phys. Chem A 1998 102, 503-507.

[40] N. Saito, P. Lemoine, S. Cordier, Y. Wada, T. Ohsawa, N. Saito, F. Grasset, J. S. Cross, N. Ohashi, CrystEngComm 2017, 19, 6028-6038. 
[41] D. H. Johnston, I. Agho, Acta Cryst. 2019, E75, 1705-1711.

[42] P. Natarajan, A. Bajpai, P. Venugopalan, J. N. Moorthy, Cryst. Growth Des. 2012, 12, 6134-6143.

[43] T. G. Gray, Chem. Eur. J. 2009, 15, 2581-2593.

[44] Z. S. Kozhomuratova, Yu. V. Mironov, M. A. Shestopalov, Y. M. Gaifulin, N. V. Kurat'eva, E. M. Uskov, V. E. Fedorov, Russ. J. Coord. Chem. 2007 33, 1-6.

[45] Z. S. Kozhomuratova, N. G. Naumov, D. Yu. Naumov, E. M. Uskov, V. E. Fedorov, Russ. J. Coord. Chem. 2007, 33, 213-221.

[46] P. C. Healy, D. L. Kepert, D. Taylor, A. H. White, J. Chem. Soc. Dalton Trans. 1973, 6, 646-650.

[47] J. P. Perdew, A. Ruzsinszky, L. G. I. Csonka, O. A. Vydrov, G. E. Scuseria, L. A. Constantin, X. Zhou, K. Burke, Phys. Rev. Lett. 2008, 100, 136406-1-4.
[48] S. J. Clark, M. D. Segall, C. J. Pickard, P. J. Hasnip, M. J. Probert, K Refson, M. C. Payne, Z. Kristallogr. 2005, 220, 567-570.

[49] F. L. Hirshfeld, Theor. Chim. Acta 1977, 44, 129-138.

[50] K. B. Wiberg, P. R. Rablen, J. Comput. Chem. 1993, 14, 1504-1518. 
Entry for the Table of Contents (Please choose one layout)

Layout 1:

\section{FULL PAPER}

We crystalized new class of the metal cluster (MC) compounds where high concentration of solvent molecules (acetone,

dichloromethane and methanol) are incorporated with $\mathrm{Cs}_{2}\left[\mathrm{Mo}_{6} \mathrm{X}_{14}\right](\mathrm{X}=$ $\mathrm{Cl}, \mathrm{Br}$ ). Their crystal structures, stabilities and electronic characteristics are discussed from the viewpoint of exploiting the MC compounds in optics and optoelectronics.

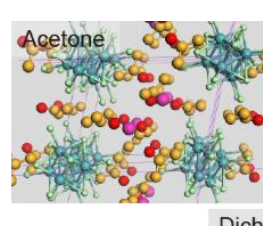

Methanol
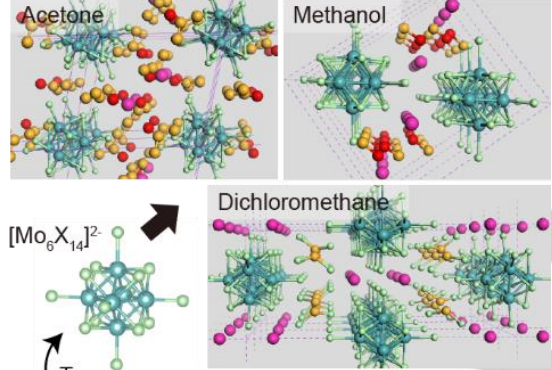

(Trap

Norio Saito, Pierric Lemoine, Stéphane Cordier, Yoshitaka Matsushita, Takeo Ohsawa, Fabien Grasset, Jeffrey Scott Cross, Naoki Ohashi

Page No. - Page No.

Structural and electronic properties of the metal cluster-based compounds including high concentration of solvent molecules

Layout 2:

\section{FULL PAPER}

((Insert TOC Graphic here; max. width: $11.5 \mathrm{~cm}$; max. height: $2.5 \mathrm{~cm}$ ))

Author(s), Corresponding Author(s)*

Page No. - Page No.

Title

Text for Table of Contents 
Additional Author information for the electronic version of the article.

Norio Saito: 0000-0002-6030-8475

Pierric Lemoine: 0000-0002-3465-7815

Stéphane Cordier: 0000-0003-0707-3774

Yoshitaka Matsushita: 0000-0002-4968-8

Fabien Grasset: 0000-0002-4911-0214 